\title{
Effects on growth of single short courses of fluoroquinolones
}

Delia B Bethell, Tran Tinh Hien, Le Thi Phi, Nicholas P J Day, Ha Vinh, Nguyen Minh Duong, Nguyen Van Len, Ly Van Chuong, Nicholas J White

\begin{abstract}
The aim of the study was to document the effects of short courses of fluoroquinolones given during an outbreak of multidrug resistant typhoid fever in southern Viet Nam on the growth of children over a period of two years. In a prospective cohort study, 326 Vietnamese children aged between 1 and 14 years were followed up for two years after receiving either ciprofloxacin $(70 \mathrm{mg} / \mathrm{kg}$ given over 7 d) $(n=173)$ or ofloxacin $(45-50 \mathrm{mg} / \mathrm{kg}$ given over 3-5 d) $(n=153)$ for suspected typhoid fever. Growth velocity and weight for height were compared with an age matched control group of children from the same locality $(n=223)$ who had not contracted typhoid or received any fluoroquinolones. In the ofloxacin and ciprofloxacin treated patients there was no evidence of acute joint toxicity, nor of any joint symptoms attributable to either of the fluoroquinolones. There was no difference in expected weight for height measurements between the three groups of children over the two year period. During the first year, height velocity in ciprofloxacin treated children was greater than in either ofloxacin treated children or untreated controls. Height velocity in the latter two groups was not significantly different. After two years height velocity was similar in the three groups. The results support the use of short course fluoroquinolone treatment in childhood typhoid, especially when caused by strains resistant to other antibiotics.

(Arch Dis Child 1996; 74: 44-46)
\end{abstract}

Keywords: fluoroquinolone, ofloxacin, typhoid, growth.

In many parts of the developing world, multidrug resistant strains of Salmonella typhi are spreading rapidly. ${ }^{1-4}$ These strains are resistant to generally available oral antimicrobial agents, but they remain highly sensitive to the fluoroquinolones. Short treatment courses with oral fluoroquinolones of just five or seven days' duration are relatively cheap, well tolerated, and very effective for the treatment of multidrug resistant typhoid fever. ${ }^{35}$ The fluoroquinolones are well absorbed broad spectrum antibiotics with an excellent safety record. ${ }^{6}$ However, their use in children has been contraindicated because of cartilage toxicity seen mainly in the weight bearing joints of young experimental animals (beagle dogs and rats). ${ }^{7-10}$ While evidence supporting the safety of fluoroquinolones in children with cystic fibrosis is accumulating gradually, ${ }^{1-14}$ most paediatricians remain unwilling to prescribe these drugs routinely. We describe here the results of a two year follow up study of children who received a single short course of either ofloxacin or ciprofloxacin during a typhoid epidemic in southern Viet Nam. We assumed that quinolone toxicity in children would present either acutely as pain in one or more weight bearing joints, or more insidiously as a detectable reduction in growth velocity over a period of one or two years.

\section{Methods}

In April 1993 the Centre for Tropical Diseases was asked to help control a typhoid epidemic affecting two hamlets in Kien Giang Province, in the Mekong Delta region of southern Viet Nam. Many of the patients were children, and two had already died. The epidemic strain of $S$ typhi was resistant to ampicillin, chloramphenicol, sulphamethoxazole, tetracycline, and trimethoprim. Thus fluoroquinolones were the only effective oral agents that could be used for treatment.

\section{Treatment}

The local health authority obtained a temporary supply of ciprofloxacin (not normally available in this area) and patients with suspected typhoid were given one week's treatment at a daily dose of $10 \mathrm{mg} / \mathrm{kg}$. Subsequent patients were randomised to receive ofloxacin for either $3 \mathrm{~d}(15 \mathrm{mg} / \mathrm{kg} / \mathrm{d})$ or $5 \mathrm{~d}(10 \mathrm{mg} / \mathrm{kg} / \mathrm{d})$ as part of a prospective therapeutic trial which has been reported elsewhere. ${ }^{15} \mathrm{~A}$ total of 286 children were treated with ofloxacin, 137 for $5 \mathrm{~d}$ and 149 for $3 \mathrm{~d}$, while 266 received ciprofloxacin.

\section{Measurements}

All patients were examined daily during treatment, and children were questioned specifically about possible symptoms of joint toxicity. Patients less than 15 years old were asked to attend follow up one, 12, and 24 months after finishing treatment, when a full history and examination was repeated, and patients and their parents were questioned retrospectively about any joint symptoms which may have occurred in the intervening period. At each visit accurate weight and height measurements, using the same scales and wall charts, were made by the same observers. 
A control group of children of a similar age and sex distribution to the ciprofloxacin and ofloxacin treated children was recruited at the one month follow up. These controls had remained well during the epidemic and had therefore not received any fluoroquinolones. They lived in the same hamlets as the treated children and, if aged over 5 years, attended the same schools. Height and weight measurements were made using the same scales and charts as for the treated children, and details of their medical histories recorded. These children were asked to attend the 12 month follow up. All patients and their attendant relatives gave fully informed consent before participating in this study.

\section{Data analysis}

For each child, growth was expressed as a percentage of the median height gain expected over one year when corrected for age and sex on standard United Kingdom growth velocity charts. ${ }^{16}$ These were used as a reference standard as local growth velocity data are not available. Percentage of expected weight for height was calculated according to standard texts. ${ }^{17}$ For each follow up period the three patient groups were compared by analysis of variance. The Bonferroni correction was applied in post hoc significance testing between pairs of groups. Repeated measures analysis of variance was used to look for differences within individual patients returning for follow up at one and two years.

\section{Results}

Oral treatment with either ciprofloxacin or ofloxacin was very well tolerated; side effects during treatment occurred rarely and were always mild. No patients had to stop treatment because of adverse effects. There was no evidence of acute joint toxicity during or after treatment. These data are described in more detail in a separate report on the efficacy of treatment. ${ }^{15}$

At the one year review, 457 children returned; 137 ciprofloxacin treated, 106 ofloxacin treated, and 214 untreated controls. After two years 549 returned $(173,153$, and 223 respectively; table). A total of 384 children attended both annual reviews $(123,87$, and
174). Baseline characteristics, including age distribution, weights, and heights, between the three groups were similar on each occasion. At the two year review all patients were aged between 3 and 16 years. None had developed any bone or joint symptoms, and none reported any tendon ruptures. Again there were no significant differences in weight for height in individual patients between the three groups.

After one year the control group grew by a mean $(95 \% \mathrm{CI})$ of $85.4 \%(81.2$ to 89.6$)$ of median expected height gain in UK children, the ciprofloxacin treated group grew by $93.2 \%$ $(87 \cdot 7$ to $98 \cdot 7)$, and the ofloxacin treated group grew by $84 \cdot 6 \%(78 \cdot 4-90 \cdot 8)$. There was no difference in growth velocity over one year between controls and ofloxacin treated children $(0.8 \%$ difference, $p=0.83)$, but ciprofloxacin treated children grew significantly more than either untreated controls $(7 \cdot 8 \%$ difference, $\mathrm{p}=0.03)$ or ofloxacin treated children (8.6\% difference, $p=0 \cdot 04)$. After two years, growth velocity was similar between the three groups. In the subgroup of 384 children who returned for follow up after both one and two years, repeated measures analysis of variance showed no demonstrable adverse effect of either drug compared with untreated controls for weight for height $(p=0.34)$ and height velocity $(p=0 \cdot 22)$.

\section{Discussion}

There was no evidence of either acute or subclinical joint toxicity in the 326 children treated with ofloxacin or ciprofloxacin who were followed up for two years in this study. In addition there were no reports of tendon rupture. ${ }^{18}$ Although only $59 \%$ of all the children who received fluoroquinolones in the typhoid epidemic were studied in this comparison with an uninfected untreated control group from the same locality, there was no systematic difference between this group and those who were not followed up, and no reason to suspect that adverse effects were unreported. This large study supports the accumulating data from studies in cystic fibrosis that the fluoroquinolone antibiotics are safe in children. ${ }^{11-14}$ These drugs offer distinct advantages over other antibiotics when used for the treatment of Gram negative infections

Baseline characteristics and results after one and two years

\begin{tabular}{|c|c|c|c|}
\hline & Untreated controls & Ciprofloxacin, $7 d$ & Ofloxacin, 3 or $5 d$ \\
\hline $\begin{array}{l}\text { Baseline } \\
\text { No } \\
\text { Age }(y) \text {, mean }(95 \% \mathrm{CI}) \\
\% \text { expected weight for height, mean }(95 \% \mathrm{CI})\end{array}$ & $\begin{array}{l}286 \\
7 \cdot 6(7 \cdot 2 \text { to } 8 \cdot 0) \\
92 \cdot 2(90 \cdot 6 \text { to } 93 \cdot 8)\end{array}$ & $\begin{array}{l}266 \\
7.8(7.4 \text { to } 8 \cdot 3) \\
91.4(89.8 \text { to } 93.0)\end{array}$ & $\begin{array}{l}286 \\
8.0(7.5 \text { to } 8 \cdot 4) \\
91.3(89.3 \text { to } 93.3)\end{array}$ \\
\hline $\begin{array}{l}\text { One year follow up } \\
\text { No }(\% \text { of baseline }) \\
\text { Age (y), mean }(95 \% \mathrm{CI}) \\
\% \text { expected weight for height, mean }(95 \% \mathrm{CI}) \\
\% \text { of UK standard height gain, mean }(95 \% \mathrm{CI})\end{array}$ & $\begin{array}{l}214(75) \\
8 \cdot 8(8 \cdot 4 \text { to } 9 \cdot 3) \\
88 \cdot 6(86 \cdot 8 \text { to } 90 \cdot 4) \\
85 \cdot 4(81 \cdot 2 \text { to } 89 \cdot 6)^{\star}\end{array}$ & $\begin{array}{l}138(52) \\
8 \cdot 7(8 \cdot 2 \text { to } 9 \cdot 3) \\
87 \cdot 6(85 \cdot 8 \text { to } 89 \cdot 4) \\
93 \cdot 2(87 \cdot 7 \text { to } 98 \cdot 7)\end{array}$ & $\begin{array}{l}106(37) \\
8 \cdot 6(8 \cdot 0 \text { to } 9 \cdot 2) \\
89 \cdot 6(87 \cdot 8 \text { to } 91 \cdot 4) \\
84 \cdot 6(78 \cdot 4 \text { to } 90 \cdot 8) \dagger\end{array}$ \\
\hline $\begin{array}{l}\text { Two year follow up } \\
\text { No (\% of baseline) } \\
\text { Age (y), mean }(95 \% \text { CI }) \\
\% \text { expected weight for height, mean }(95 \% \mathrm{CI}) \\
\% \text { of UK standard height gain over } 2 \text { years, mean }(95 \% \mathrm{CI})\end{array}$ & $\begin{array}{l}223(77) \\
10 \cdot 1(9 \cdot 7 \text { to } 10 \cdot 6) \\
88 \cdot 3(86 \cdot 5 \text { to } 90 \cdot 1) \\
92 \cdot 7(89 \cdot 2 \text { to } 96 \cdot 2)\end{array}$ & $\begin{array}{l}173(65) \\
9 \cdot 6(9 \cdot 1 \text { to } 10 \cdot 0) \\
87.5(85.9 \text { to } 89 \cdot 1) \\
89.9(86.9 \text { to } 92 \cdot 8)\end{array}$ & $\begin{array}{l}153(53) \\
9 \cdot 9(9 \cdot 4 \text { to } 10 \cdot 4) \\
89 \cdot 7(87 \cdot 7 \text { to } 91 \cdot 7) \\
91 \cdot 1(87 \cdot 2 \text { to } 95 \cdot 1)\end{array}$ \\
\hline
\end{tabular}


because of their acceptability, rapid oral absorption, good intracellular penetration, and speed of action. ${ }^{619}$ Salmonellae are extremely sensitive, and multidrug resistant infections can be cured with only three days of treatment. ${ }^{15}$ Indeed there is no orally active alternative for the treatment of multidrug resistant infections with $S$ typhi.

The height gains overall in this series were less then predicted from the TannerWhitehouse charts, which were derived from observations in English schoolchildren 20 years ago (as local data are not available). This was expected, as overall heights in Viet Nam are lower than in the United Kingdom. The results suggested improved growth over one year after a week's course of ciprofloxacin at a relatively high dose. This was not a randomised study, and so there may have been some selection bias to account for the differences in growth observed between the groups. However, the improved growth in the ciprofloxacin group could have resulted from an antibacterial effect. The study was carried out in a poor rice farming community where many of the children were undernourished and may have had intestinal microflora which impaired intestinal nutrient absorption. Abnormalities in jejunal microflora have been widely implicated in the diarrhoea-malabsorption-malnutrition cycle. ${ }^{2021}$ This is treatable with antibiotics. The fluoroquinolones are known to reach very high concentrations in the intestine and may have been acting against upper gastrointestinal microflora which were impairing absorption. The ofloxacin treated patients did not show any growth advantage after one year, but these patients received shorter courses of treatment and approximately half the antibiotic dose overall compared to the ciprofloxacin treated children. The observed differences in height velocity had disappeared at the two year review.

On the basis of these and other data there seems no reason to withhold short courses of fluoroquinolones from children when alternative unrestricted therapies are either unavailable or inappropriate.
The authors thank the Kien Giang Health Services and the Director and staff of the Centre for Tropical Diseases for their help and support during the course of this study. Ofloxacin was kindly provided by Professor A Bryskier of Roussell-UCLAF kindly provided by Professor A Bryskier of Roussell-UCLAF
Pharmaceuticals, Paris. This study was funded by the Wellcome Pharmaceuticals, Paris.
Trust of Great Britain.

1 Mourad AS, Metwally M, Deen ANE, et al. Multiple-drug resistant Salmonella typhi. Clin Infect Dis 1993; 17: 135-6. resistant Salmonella typhi. Clin Infect Dis 1993; 17: 135-6.
Uwaydah AK, Matar I, Chacko KC, Davidson JC. The emergence of antimicrobial resistant Salmonella typhi in Qatar: epidemiology and therapeutic implications. Trans $R$ Soc Trop Med Hyg 1991; 85: 790-2.

3 Smith MD, Duong NM, Hoa NTT, et al. Comparison of ofloxacin and ceftriaxone for short-course treatment of enteric fever. Antimicrob Agents Chemother 1994; 38: 1716-20.

4 Wallace M, Yousif AA. Spread of multiresistant Salmonella typhi. Lancet 1990; 336: 1065-6.

5 Hien.TT, Duong NM, Ha HD, et al. A randomised comparative study of fleroxacin and ceftriaxone in enteric fever. Trans R Soc Trop Med Hyg 1994; 88: 464-5.

6 Hooper DC, Wolfson JS. Fluoroquinolone antimicrobial agents. N Engl f Med 1991; 324: 384-94.

7 Burkhardt JE, Hill MA, Carlton WW, Kesterson JW. Histologic and histochemical changes in articular Histologic and histochemical changes in articular
cartilages of immature beagle dogs dosed with difloxacin cartilages of immature beagle dogs dosed with
fluoroquinolone. Vet Pathol 1990; 27: 162-70.

8 Gough A, Barsoum NJ, Mitchell L, McGuire EJ, Iglesia FA. Juvenile canine drug-induced arthropathy: clinicopathological studies on articular lesions caused by oxolinic and pipemidic acids. Toxicol Appl Pharmacol 1979; 51: 177-87.

9 Maggiolo F, Caprioli S, Suter F. Risk/benefit analysis of quinolone use in children: the effect on diarthrodial joints. f Antimicrob Chemother 1990; 26: 469-71.

10 Stahlmann R, Merker HJ, Hinz N, et al. Ofloxacin in juvenile non-human primates and rats. Arthropia and drug plasma concentrations. Adv Toxicol 1990; 64: 193-204.

11 Schaad UB, Mohammed AS, Yannick A, et al. Use of fluoroquinolones in pediatrics: consensus report of an International Society of Chemotherapy commission. Pediatr Infect Dis $\mathcal{F} 1995$; 14: 1-9.

12 Sshaad UB, Wedgwood J. Lack of quinolone-induced arthropathy in children. $\mathcal{f}$ Antimicrob Chemother 1992; 30: arthrop

13 Schaad UB, Stoupis C, Wedgwood J, Tschaeppeler H, Vock P. Clinical, radiologic and magnetic resonance monitoring for skeletal toxicity in pediatric patients with cystic fibrosis receiving a three-month course of ciprofloxacin. Pediatr Infect Dis f 1991; 10: 723-9.

$14 \mathrm{LeBel} M$. Fluoroquinolones in the treatment of cystic fibrosis: a critical appraisal. Eur f Clin Microbiol Infect Dis 1991; 10: $316-24$.

15 Hien TT, Bethell DB, Hoa NTT, et al. Short course ofloxacin treatment of multi-drug resistant typhoid. Clin Infect Dis 1995; 20: 917-23.

16 Tanner JM, Whitehouse RH. Clinical longitudinal standards for height, weight, height velocity, weight velocity, and stages of puberty. Arch Dis Child 1976; 51: 170-9.

17 Waterlow JC. Protein-energy malnutrition. 2nd Ed. London: Edward Arnold, 1992.

18 Royer RJ, Pierfitte C, Netter P. Features of tendon disorders with fluoroquinolones. Therapie 1994; 49: 75-6.

19 Adam D. Use of quinolones in pediatric patients. Rev Infect Dis 1989; 11 (suppl 5): S1113-6.

20 Heyworth B, Brown J. Jejunal microflora in malnourished Gambian children. Arch Dis Child 1975; 50: 27-33.

21 Hirschhorn N. Can small daily doses of antibiotics prevent the cycle of diarrhea, malabsorption, and malnutrition in children? Am f Clin Nutr 1971; 24: 872-5. 